\title{
LOCATOR VS TELESCOPIC CROWN ATTACHMENTS FOR MAXILLARY IMPLANT OVERDENTURE. A WITHIN-SUBJECT STUDY OF CHEWING EFFICIENCY AND MAXIMUM BITE FORCE
}

\author{
Mohamad Hossam El-Din Helmy* and Mohammed M. Elsokkary*
}

\begin{abstract}
Aim: This within-subject study report to investigate masticatory efficiency and maximum bite force of Locator and telescopic crown attachments used to retain maxillary implant overdentures.

Materials and methods: Six edentulous patients ( 3 males and 3 females) received 4 implants in the anterior maxillary region between the maxillary sinuses using a standardized 2 stage surgical approach. Six months after osseointegration, the implants were loaded either by Locator or telescopic maxillary overdentures in a cross-over study design. Masticatory efficiency was performed using the 2-colored gum mixing ability test. The gum was chewed for 5, 10, 20, 30, and 50 cycles, and the images of the chewed gum were analyzed using a Photoshop program to calculate the unmixed fraction (UF). Also, maximum bite force was evaluated using a bite-force transducer. Chewing efficiency and maximum bite forces were evaluated 3 months after wearing each overdenture.
\end{abstract}

Results: The success rate was $100 \%$ in both groups. There was a trend for a decrease in UF (ie improved masticatory efficiency) with the increase in the number of masticatory cycles. Telescopic maxillary overdentures showed significantly lower UF (ie higher masticatory efficiency) and higher maximum bite force than Locator maxillary overdentures

Conclusion: Telescopic attachments are recommended for maxillary implant overdentures as it had improved masticatory efficiency and maximum bite force than Locator attachments

\section{INTRODUCTION}

The maxillary implant overdenture is a widely used treatment modality for edentulous patients who complaining of a lack of retention and stability of their conventional maxillary dentures ${ }^{1}$. Such prosthesis has obvious merits in several clinical situations as maxillary ridge resorption with insufficient bone volume especially in the posterior regions, need for adequate lip support for esthetics, increased interarch space and long clinical crowns if fixed restoration is used, abnormal jaw relations (class II and class III angle classification) and implant inclination in the premaxillary regions ${ }^{2}$.

\footnotetext{
* Lecturer, Removable Prosthodontic Department, Faculty of Dentistry, Assiut University
} 
Furthermore, maxillary overdentures can be considered an emergency treatment option for failing fixed prosthesis in patients who have natural teeth or fixed restoration in the opposing mandible ${ }^{2,3}$. Moreover, performing oral hygiene is easier than fixed maxillary prosthesis ${ }^{4}$ For maxillary implant overdentures several factors should be considered in the treatment plan such as they may affect the success of the treatment as; the lower quality of bone, the muscles of mastication, the type of opposing occlusion, the type of attachments, the interarch distance, and implant angulation ${ }^{5}$. Based on survival rate studies, four implants are considered the minimum number needed for overdenture treatment ${ }^{6}$

The type of attachment system may affect the implant success rate for maxillary overdentures as it may affect the pattern of loading around implants ${ }^{7}$. Moreover, the amount of retention and stability given by various attachments may affect the masticatory functions as muscle activity, chewing efficiency, and maximum bite force ${ }^{8,9}$. In a systematic review, Sadowsky ${ }^{10}$ did not found a difference between the implant survival rate of splinted and unsplinted implants.

Several attachment systems may be used to retain maxillary overdentures such as splinted and unsplinted systems ${ }^{11}$. There Unsplinted attachments (ball, Locator, and telescopic crowns) have several advantages such as minimum space required in the denture base, reduced costs, and easy to perform oral hygiene compared to splinted designs. ${ }^{12}$ It also allows for more flexibility in implant positioning, when there are anatomic limitations..$^{13}$ On the other hand, splinted attachments (bars with different cross-sections) are technically more complex, require a minimum distance of $13-14 \mathrm{~mm}$ from the implant platform to the incisal edges (for the bar/ clips and the space under the bar for oral hygiene in addition to the space for the teeth and the denture base), Moreover, the oral hygiene under the bar is more complicated than solitary attachments ${ }^{14}$
Telescopic attachments are composed of primary (inner) and secondary (outer) crowns. Telescopic attachments may be rigid ones which include friction parallel walls or the conical, and the nonrigid (resilient) ones. Rigid telescopic crowns direct occlusal contact between inner and outer copings. They achieve retention using the friction of parallel-sided milled surfaces of the inner and outer crowns during insertion and removal. Conical (tapered) telescope crowns exhibit friction only when completely seated using a "wedging effect." ${ }^{15-17}$. Telescopic attachments provide several advantages compared to bar attachments such as easier oral hygiene, self-insertion ability in patients with handling problems, high retention by friction, excellent denture support and stability especially in patients with atrophied ridges, and minimal restriction of tongue space ${ }^{17-19}$ The Locator attachment is a selfaligning, have internal and external flange retention with different values of retention (color coded), ${ }^{11}$ provide increased retention and stability ${ }^{20}$, and can be used with decreased interarch space to reduce denture base fracture thanks to their low profile ${ }^{21}$. Locators also can be used with angulated individual implants up to $40^{\circ} 22$ without problems and can be easily replaced when retention is lost ${ }^{23}$.

Implant-supported overdentures have been reported to improve muscle activity, chewing efficiency, and comfort compared to conventional dentures ${ }^{24-28}$ compared with conventional complete dentures. Moreover, such prosthesis can enhance biting and chewing, and can improve patient satisfaction $^{29,30}$.

Several methods of measuring masticatory efficiency were reported as the estimation of the sizes of chewed particles, maximum biting force ${ }^{31}$, mastication time, the total number of masticatory cycles ${ }^{32,33}$, sieving method, and two-colour chewing gum $^{34,35}$. The improvement of chewing efficiency may depend on the amount of retention and stability of the denture and thus on the type of retention 
mechanism ${ }^{36,37}$. Accordingly, the aim of present cross-over study to investigate chewing efficiency and bite force of Locator and telescopic crown retained maxillary implant overdentures.

\section{MATERIAL AND METHODS}

\section{Enrollment of the participants and study design}

Six edentulous patients $(3$ males and 3 females) were selected from patients attending the prosthodontic department. All patients complained of insufficient attention and stability of the exiting maxillary dentures and needed a more stable prosthesis. The inclusion criteria include: 1) sufficient to bone volume and quality in the area between the maxillary sinuses as detected by cone beam computerized tomography to receive 4 implants (at at least $10 \mathrm{~mm}$ in length and $4 \mathrm{~mm}$ in diameter), 2) all participants had sufficient interarch space, 3) All patients had conventional mandibular dentures. The patients were excluded if they had one or more of the following conditions: 1) smoking habit, 2) diabetes Mellitus or any systemic disease that may affect the bone metabolism, 3) radiotherapy or chemotherapy to the head and neck region. The study protocol was approved by the ethical committee of the faculty. Informed consents were obtained from all participants. All patients received 4 implants in the anterior maxillary region. The study was conducted within the same participant in a cross-over design, ie each patient has received 2 types of prostheses (telescopic and locator overdentures). The patients were rundomly assigned into two blocks by rundom numbers on excel sheet (each block contains 3 patients). The first block received Locator retained maxillary overdentures first and after 3 months of wearing the dentures, chewing efficiency and maximum bite force were measured. Then they received telescopic retained maxillary overdentures and after another 3 months, the measurements were repeated. The second block received telescopic retained maxillary overdentures first and after 3 months of wearing the dentures chewing efficiency and maximum bite force were measured. Then they received Locator retained maxillary overdentures and after another 3 months, the measurements were repeated. The aim of this randomization was to avoid the effect of the order of the attachment type on the measurements.

\section{Surgical and prosthetic procedures}

The maxillary old denture was duplicated to be used as a radiographic template. The gutta perchae was added to the polished bucca and palatal surfaces of the denture to be used as radiopaque markers. Cone-beam computerized tomography (i- CAT, USA) was performed using the dual scan protocol (while the patient wearing the denture and with the denture alone $)^{38}$. The optimal location and angulation of the implants and the correct implant length were planned. A bone-supported surgical guide was constructed by prototyping technology using 3D image-based software (OnDemand3DApp Software; CyberMed Inc). A surgical kit including sleeves and standardized drills (supplied by the radiologist) was used for osteotomy preparation.

Each patient received 4 implants (Dentaurum, Germany), in the anterior part of the maxilla between maxillary sinuses using a standardized 2 stage surgical approach. All surgeries were carried out with infiltration anesthesia (lidocaine with epinephrine). A mid-crestal incision was made from the premolar area on one side to the premolar area on the other side. Full-thickness mucoperiosteal flap was raised. The surgical guide was fixated in place using the fixation pins. Successive drilling was made using drills of increasing diameters. If the bone quality was low, the last drill was omitted to increase the implant stability. The 3.3- and 3.7-mm twist drills were used as the final drills for $3.7 \mathrm{~mm}$ and $4.2 \mathrm{mmm}$ diameter implants respectively in case of Class III and IV quality bone ${ }^{39}$. The cover screws were placed, and the flap was closed with interrupted sutures. The denture was relieved opposite to the implants and relined with a soft liner. 
6 months later, the implants were uncovered after minimal flap reflection and healing abutments were connected. After 2 weeks, Open tray impression procedure was started. A custom acrylic tray was constructed with perforations on the implant positions. Long impression posts were threaded to the implants and splinted inpatient mouth using a special resin to avoid accidental movement of the transfer during impression removal (fig1).

Light consistency rubber base impression was loaded around the impression posts and the overall impression was made using putty material (Zhermack®), Badia Polesine, Rovigo, Italy). Implant analogs were attached to the impression posts and the impression was poured. For Locator

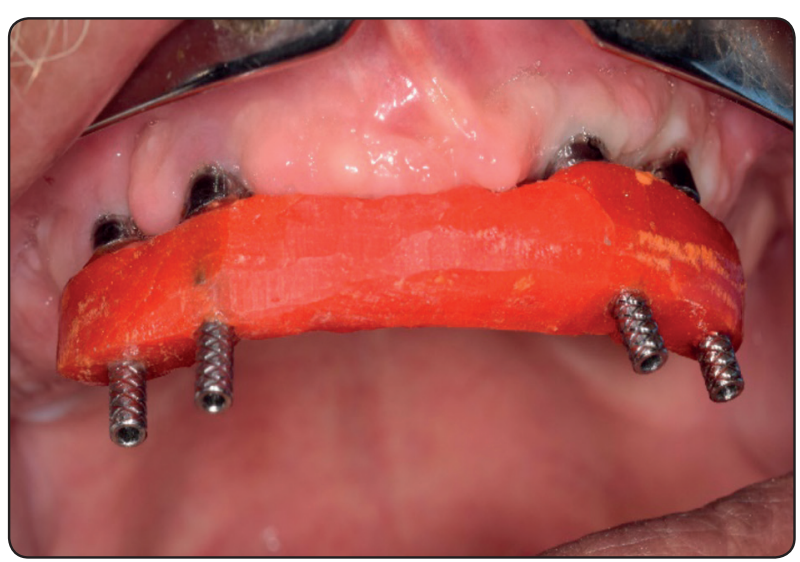

Fig. (1) Splinting the transfer copings with "duralay" acrylic resin maxillary overdenture group, locator abutments (Dentaurum, Germany) were threaded to the implant analogs. White blocking rings were placed over the abutments to relieve acrylic resin around the abutments. Metal housing with black processing inserts were snapped on the locator abutments. The maxillomandibular relations were recorded. The bilateral balanced occlusal concept was used. Packing of acrylic resin and denture processing was performed in the usual manner. Black processing inserts were removed using locator tool and replaced with blue nylon insert (extra light retention) and dentures delivered to the participants (fig 2).

For the Telescopic maxillary overdenture group, 4 precious metal abutments (Dentaurum, Germany) were threaded to the implant analogs. The plastic portions of the abutments were waxed and milled with $2^{\circ}$ inclination burs using a milling device to give the primary (inner) copings $(6 \mathrm{~mm}$ in height and $5 \mathrm{~mm}$ in diameter). The 4 wax patterns were milled to make their circumferential walls parallel to each other's in mesiodistal and buccolingual direction regardless of implant inclination. The wax was invested, cast in cobalt-chromium alloy ${ }^{40-42}$ (Heraenium Pw, Heraeus-Kulzer GmbH, Hanau, Germany), and refined by milling again and tried in the patient mouth. Four secondary copings were designed over the primary copings with a $1.0 \mathrm{~mm}$ -

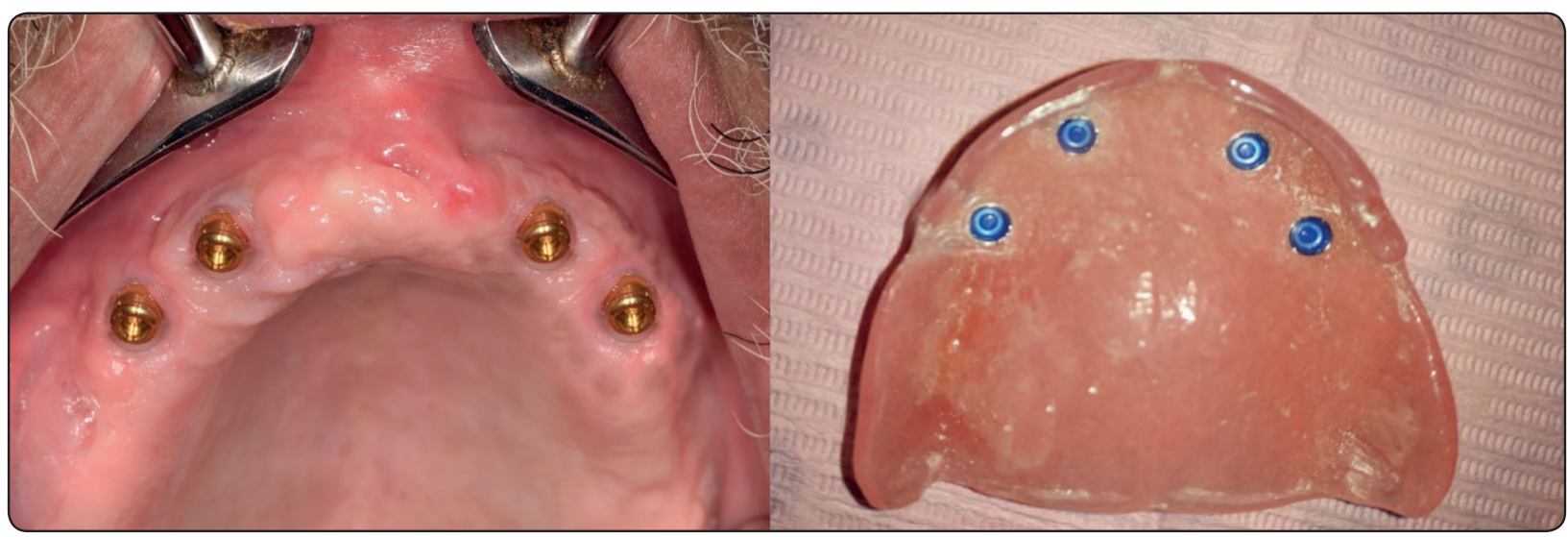

Fig. (2) Locator maxillary overdentures; a) the Locator abutments in the patient mouth, b) the metal housing with blue nylon inserts attached to the fitting surface of the denture. 
thickness to cover the primary copings, invested and cast with cobalt-chromium alloy. The secondary copings were placed over the primary copings on the master cast. Jaw relations were recorded. The bilateral balanced occlusal concept was used. Packing of acrylic resin and denture processing was performed in the usual manner (fig 3).

The overdentures were finished and delivered to the patients with emphasis on oral hygiene procedures, and follow-up visits were scheduled with patients on 3 months' regular recalls.

\section{Measurement of masticatory efficiency}

Measurement of masticatory efficiency was performed using the 2-colored gum mixing ability test $^{34,35}$. Two pieces $(30 \times 18 \times 3 \mathrm{~mm})$ in size of Gum of 2 colors; one with the taste 'mint flavor' (white color) and one with taste 'Strawberry Fruit' (red color) were staked together. The subjects were informed to masticate 5 gums for 5, 10, 20, 30, and 50 cycles. The chewed gums were spat and flattened to $1 \mathrm{~mm}$ thickness in nylon transparent bags. The gums were scanned and standardized in size, resolution and dimensions. Using Adobe Photoshop ${ }^{\circledR}$ software, the 'magic wand' tool was used to select the unmixed red pixels (fig4). The numbers of selected pixels were calculated from the histogram. Subsequently, Unmixed Fraction (UF) is calculated as:
(Pixels red side a+ Pixels red side $b$ ) - $2 \times$ Pixels of scale

$$
2 \times \text { Pixels }_{\text {all }}
$$

The increased UF means a decrease in chewing efficiency and vice versa.

\section{Evaluation of maximum bite force}

Occlusal bite forces were measured bilaterally with a bite-force transducer ${ }^{43}$ (Type EA-06125MW-120, Measurements Group Inc., Raleigh, NC, USA) which had a bite fork placed between the posterior artificial teeth. The patients were asked to do a maximum biting on the fork of the transducer for 5 seconds. The measurements were repeated 3 times after five minutes of resting. The highest bite force (in newton, $\mathrm{N}$ ) of the 3 measurements was used.

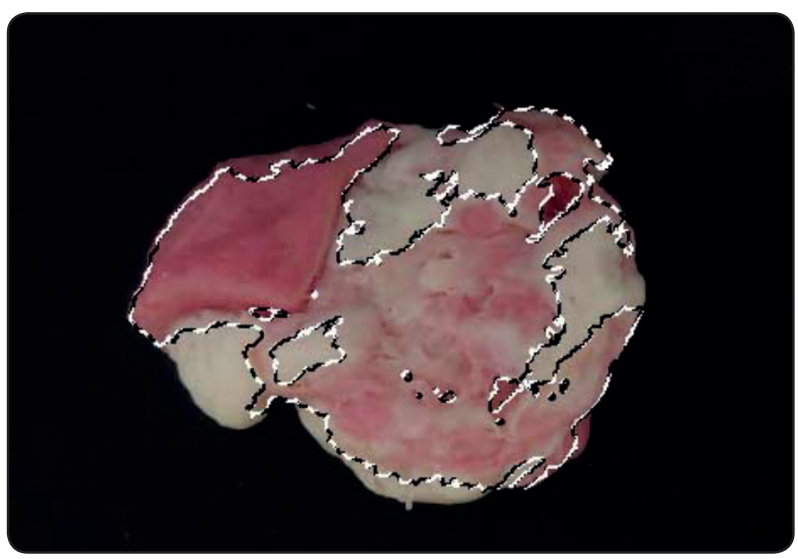

Fig. (4) Selection of the unmixed pixels using the magic wand tool of the Photoshop software.

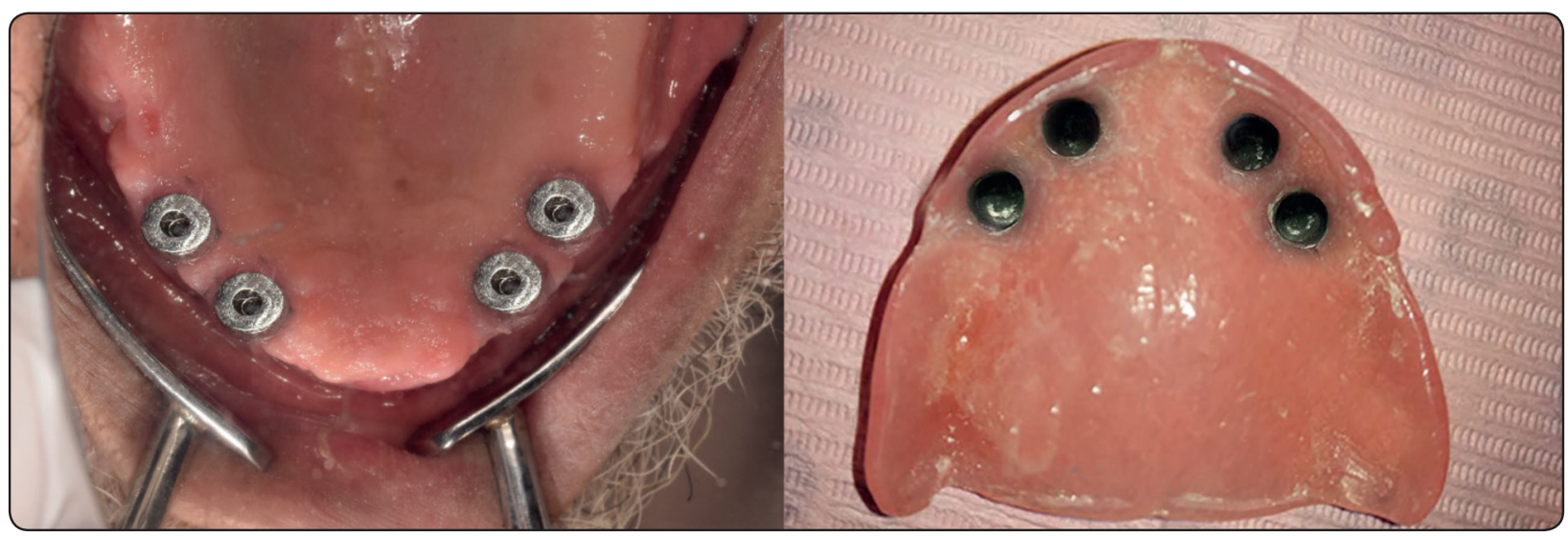

Fig. (3) Telescopic maxillary overdentures; a) the primary copings in the patient mouth, b) the secondary copings attached to the fitting surface of the denture. 
For each participant, masticatory efficiency and maximum bite force were measured 3 months after wearing 1) Locator retained maxillary overdentures, and 2) Telescopic retained maxillary overdentures.

\section{Statistical analysis}

The assumption of the normality of the collected data was tested by the Shapiro-Wilk test. The data was parametric and meet the normal distribution. To compare UF values and maximum bite forces (in $\mathrm{N}$ ) between attachments, independent samples t-test was utilized. To compare UF values between masticatory strokes $(5,10,20,30$, and 50 cycles), repeated-measures ANOVA was used by the
Bonferroni test for pair-wise comparisons. $\mathrm{P}$ is significant if it was less than .05 for all analyses.

\section{RESULTS}

The implant success rate was $100 \%$ in both groups as no implant failures occurred. Comparison of unmixed fraction (UF) between attachments and different masticatory cycles is presented in table 1 . Descriptive statistics included mean, standard deviation, median, minimum and maximum and are presented in table 1. For both groups (overdentures), there was a statistically significant difference in UF between numbers of masticatory cycles $(\mathrm{P}<.001)$. For both groups, the highest UF was noted with

TABLE (1) Comparison of unmixed fraction (UF) between attachments and different masticatory cycles.

\begin{tabular}{|c|c|c|c|c|}
\hline & & Locator maxillary overdentures & Telescopic maxillary overdentures & Independent t-test \\
\hline & Mean & $.7073 \mathbf{A}$ & $.6405 \mathrm{~A}$ & \\
\hline & Median & .00646 & .00484 & \\
\hline Five masticatory & $S D$ & .7068 & .6383 & $\mathrm{P}=.003^{*}$ \\
\hline & Minium & .70 & .64 & \\
\hline & Maximum & .72 & 65 & \\
\hline & Mean & $.7042 \mathrm{~A}$ & $.6345 \mathrm{~A}$ & \\
\hline & Median & .00759 & .00382 & \\
\hline Ien masticatory & $S D$ & .7035 & .6365 & $\mathrm{P}<.001 *$ \\
\hline & Minium & .69 & .63 & \\
\hline & Maximum & .72 & .64 & \\
\hline & Mean & 6892B & $.6216 \mathbf{B}$ & \\
\hline Twenty & Median & .00232 & .00404 & \\
\hline masticatory & $S D$ & 6890 & 6220 & $\mathrm{P}=.001 *$ \\
\hline cycles & Minium & .69 & .62 & \\
\hline & Maximum & .69 & .63 & \\
\hline & Mean & $.6868 \mathbf{B}$ & $.6128 \mathbf{B}$ & \\
\hline Thirty & Median & .01220 & .00382 & \\
\hline masticatory & $S D$ & .6870 & .6120 & $\mathrm{P}=.002^{*}$ \\
\hline cycles & Minium & .67 & .61 & \\
\hline & Maximum & .70 & .62 & \\
\hline & Mean & $.6650 \mathrm{C}$ & $.5764 \mathrm{C}$ & \\
\hline & Median & .00676 & .00370 & \\
\hline Firetymasticatory & & .6669 & .5765 & $\mathrm{P}<.001 *$ \\
\hline cycies & Minium & .66 & .57 & \\
\hline & Maximum & .67 & .58 & \\
\hline Repeated measure & S ANOVA & $\mathrm{P}<.001^{*}$ & $\mathrm{P}<.001 *$ & \\
\hline
\end{tabular}

SD; Standard Deviation. * p is significant at 5\% level. Different letters in the same column indicated a significant difference between the numbers of chewing strokes (Bonferroni test, $p<.05$ ) 
5 cycles and 10 cycles (without difference between 5 and 10 cycles), followed by 20 and 30 cycles (without difference between 20 and 30 cycles), and the lowest UF was observed with 50 cycles. There was a trend for a decrease in UF (ie improved masticatory efficiency) with the increase in the number of masticatory cycles. Multiple comparisons between numbers of masticatory cycles are presented in table 1 for both groups. No significant difference between 5 and 10 cycles nor between 20 and 30 cycles was noted. There was a significant difference between $5 / 10$ cycles and 20/30 cycles and between 5/10 cycles and 50 cycles. Also, there was a significant difference between $20 / 30$ cycles and 50 cycles. Table 1 shows a comparison of UF between groups (attachments). For all numbers of chewing cycles, there was a significant difference in UF between groups.

TABLE (2) Comparison of maximum bite force between attachments

\begin{tabular}{|c|c|c|c|}
\hline & $\begin{array}{c}\text { Locator } \\
\text { maxillary } \\
\text { overdentures }\end{array}$ & $\begin{array}{c}\text { Telescopic } \\
\text { maxillary } \\
\text { overdentures }\end{array}$ & $\begin{array}{c}\text { Independent } \\
\text { t-test }\end{array}$ \\
\cline { 1 - 3 } Mean & 71.00 & 102.17 & \\
\cline { 1 - 2 } Median & 69.40 & 100.65 & \multirow{2}{*}{$\mathrm{P}=.003^{*}$} \\
\cline { 1 - 3 } SD & 8.00 & 9.00 & \\
\cline { 1 - 2 } Minium & 60.00 & 90.00 & \\
\cline { 1 - 2 } Maximum & 80.00 & 110.00 & \\
\hline
\end{tabular}

Telescopic maxillary overdentures showed significantly lower UF (ie higher masticatory efficiency than Locator maxillary overdentures) at 5, 10, 20, 30, and 50 masticatory cycles.

Comparison of maximum bite force between attachments is presented in table 2. Descriptive statistics included mean, standard deviation, median, minimum and maximum and are presented in the same table. Telescopic maxillary overdentures showed significantly higher maximum bite force than Locator maxillary overdentures $(\mathrm{p}=.003)$

\section{DISCUSSION}

Chewing efficiency depends mainly on food comminutions, therefore it depends on withinpatient anatomical factors such as activity and tonicity of muscles of mastication, jaw relations, and ridge anatomy. Other sociodemographic data of the patients such as age and gender also may affect the muscle activity and masticatory efficiency. Therefore the cross-over design used in this study helped to standardize these factors and make the measurements of chewing efficiency more reliable ${ }^{34}$. Colored chewing gum was used to evaluate masticatory efficiency based on recommendations of several previous studies ${ }^{34,35,44}$. The gum has several merits such as availability, simplicity and cost-effectiveness in comparison to other methods used to evaluate chewing efficiency. Moreover, the increased color mixing indicates higher chewing efficiency because the color mixing resulted from extraction and leaching out of the sweetening components. In addition, the use of chewing gum does not allow stagnation of food particles under the dentures or swallowing of these particles and thus may be lost and not evaluated ${ }^{45}$.

The UF decreased with the increased number of chewing strokes. This could be attributed to the increased color mixing together with leaching out of the colored components of the gum with the increased number of chewing strokes (cycles) ${ }^{35}$. Similarly, in another cross-over study ${ }^{34}$, the investigators showed a similar finding when they compared chewing efficiency and muscle activity of 3 attachments used for mandibular implant assisted overdentures. However, no significant difference between 5 and 10 cycles nor between 20 and 30 cycles was noted. This indicates that the effect of color mixing (chewing efficiency) was not evident except after 10 cycles, then after 30 cycles. Therefore, it may be recommended in future studies to evaluate chewing efficiency at 10, 30, and 50 chewing cycles only to save time and effort 
From the results of this study, telescopic maxillary overdentures showed significantly lower UF (ie higher masticatory efficiency) and maximum bite force than Locator maxillary overdentures. The increased retention and stability of the telescopes compared to locators may explain this result. The patient's ability to comminute food is more dependent on the degree of retention and stability of the dentures, rather than the supporting elements ${ }^{46}$. The increased retention and stability for telescopic attachments come the apical friction between the primary and secondary copings and the increased vertical dimensions of the telescopic attachments ${ }^{47}$. The increased retention and stability of telescopic attachments concurred with another study ${ }^{48}$ in which the authors noted that casting nodules on the surfaces of the secondary crowns create wear tracks (scratches) on the polished surface of the primary crowns which may result in cold metal fusion and increased adhesive friction and retention of telescopic attachments used to retain maxillary overdentures. The authors added that telescopic attachments also provide excellent stability (limiting of side by side movement) due to the increased vertical height of the attachment which makes it disconnect slowly during nonaxial dislodgement. The increased denture stability and retention provide stable occlusion, good chewing, and favor axial loading of the implants ${ }^{19,49}$ and enhance food grinding ${ }^{46}$. In line with this observation, Heckmann, et al. ${ }^{17}$ observed an increase in chewing ability, maximum bite force and improvement of denture handling when resilient telescopic attachments were used for 2-implant retained mandibular overdentures. The high retention and stability of telescopic maxillary overdentures improve muscle activity ${ }^{36,37}$ and increase maximum bite forces ${ }^{19,49}$ and increase the ability to grind foods. In addition, the increased vertical height of the attachment can cause an increased tactile sensation, osseopreception, and increased axial transmission of masticatory force to the ridges ${ }^{19,49}$. As a result, extensive occlusal forces produced before triggering of periosteal mechanoreceptors adjacent to the dental implant which favors increased maximum bite forces and improved masticatory efficiency ${ }^{50,51}$.

On the other hand, reduced chewing efficiency and maximum bite force with locator maxillary overdentures may be related to the resilient matrix used with this attachment which allows vertical, and rotational movement of the overdentures. Therefore, support, retention, and stability are reduced compared to the rigid telescopic attachment. Also, the reduced vertical height of the attachments makes the attachment disengage more easily especially with non-axial dislodging forces that may occur during mastication. This particularly occurs due to implant inclination in the premaxillary region. Therefore, the retention and stability are significantly reduced during axial and non-axial dislodging forces. In line with this explanation, Elsyad et al..$^{52}$ found that moderate labial implant inclination $\left(10^{\circ}\right.$ and $\left.20^{\circ}\right)$ negatively affects retention and stability of locator overdentures. Consequently, the reduced retention and stability can minimize chewing efficiency. Moreover, the decreased vertical height of the Locator attachment can reduce tactile sensation, osseopreception as the dentures gain more tissue support than telescopic attachment. Therfore, maximum bite forces and chewing efficiency decreased

Despite the improved chewing efficiency and maximum bite forces with telescopic maxillary overdentures compared to Locator overdentures, Khalid et al. $^{53}$, found no significant difference in patients' OHIP between implant-supported overdentures with telescopic crown or locator attachments. The limitations of this study include the small sample size, the short follow-up period, and the lack of control (conventional denture) group. Therefore, future research with sufficient followup periods are still recommended. Also studying different types of opposing mandibular dentitions is recommended as it may affect the results of chewing efficiency and bite forces of the tested attachments. 


\section{CONCLUSION}

Within the limitations of this study, regarding the small sample size and the short observation time, telescopic attachments are recommended to retain maxillary implant overdentures as it was associated with improved msticatory efficiency and maximum bite force than Locator attachments

\section{REFERENCES}

1. Visser A, Raghoebar GM, Meijer HJ, Vissink A. Implantretained maxillary overdentures on milled bar suprastructures: a 10-year follow-up of surgical and prosthetic care and aftercare. Int J Prosthodont. 2009; 22:181-92.

2. Mericske-Stern RD, Taylor TD, Belser U. Management of the edentulous patient. Clin Oral Implants Res. 2000;11 Suppl 1:108-25.

3. Jemt T, Book K, Karlsson S. Occlusal force and mandibular movements in patients with removable overdentures and fixed prostheses supported by implants in the maxilla. Int $\mathbf{J}$ Oral Maxillofac Implants. 1993;8:301-8.

4. Naert I, Gizani S, van Steenberghe D. Rigidly splinted implants in the resorbed maxilla to retain a hinging overdenture: a series of clinical reports for up to 4 years. J Prosthet Dent. 1998;79:156-64.

5. Damghani S, Masri R, Driscoll CF, Romberg E. The effect of number and distribution of unsplinted maxillary implants on the load transfer in implant-retained maxillary overdentures: an in vitro study. J Prosthet Dent. 2012;107:358-65.

6. Jivraj S, Chee W, Corrado P. Treatment planning of the edentulous maxilla. Br Dent J. 2006;201:261-79; quiz 304.

7. Slot W, Raghoebar GM, Vissink A, Huddleston Slater JJ, Meijer HJ. A systematic review of implant-supported maxillary overdentures after a mean observation period of at least 1 year. J Clin Periodontol. 2010;37:98-110.

8. Elsyad MA, Khairallah AS. Chewing efficiency and maximum bite force with different attachment systems of implant overdentures: a crossover study. Clin Oral Implants Res. 2017;28:677-82.

9. Elsyad MA, Shawky AF. Masticatory functions with ball and resilient telescopic anchors of mandibular implant overdentures. A cross over study Quintessence Int. 2017;48:615-23.
10. Sadowsky SJ. Treatment considerations for maxillary implant overdentures: a systematic review. J Prosthet Dent. 2007;97:340-8.

11. Trakas T, Michalakis K, Kang K, Hirayama H. Attachment systems for implant retained overdentures: a literature review. Implant Dent. 2006;15:24-34.

12. Watson CJ, Tinsley D, Sharma S. Implant complications and failures: the complete overdenture. Dent Update. 2001;28:234-8, 40 .

13. Narhi TO, Hevinga M, Voorsmit RA, Kalk W. Maxillary overdentures retained by splinted and unsplinted implants: a retrospective study. Int $\mathbf{J}$ Oral Maxillofac Implants. 2001;16:259-66.

14. Phillips K, Wong KM. Space requirements for implantretained bar-and-clip overdentures. Compend Contin Educ Dent. 2001;22:516-8, 20, 22.

15. Heckmann SM, Winter W, Meyer M, Weber HP, Wichmann MG. Overdenture attachment selection and the loading of implant and denture-bearing area. Part 2: A methodical study using five types of attachment. Clin Oral Implants Res. 2001;12:640-7.

16. Heckmann SM, Winter W, Meyer M, Weber HP, Wichmann MG. Overdenture attachment selection and the loading of implant and denture-bearing area. Part 1: In vivo verification of stereolithographic model. Clin Oral Implants Res. 2001;12:617-23.

17. Heckmann SM, Schrott A, Graef F, Wichmann MG, Weber HP. Mandibular two-implant telescopic overdentures. Clin Oral Implants Res. 2004;15:560-9.

18. Eitner S, Schlegel A, Emeka N, Holst S, Will J, Hamel J. Comparing bar and double-crown attachments in implant-retained prosthetic reconstruction: a follow-up investigation. Clin Oral Implants Res. 2008;19:530-7.

19. Hoffmann O, Beaumont C, Tatakis DN, Zafiropoulos GG. Telescopic crowns as attachments for implant supported restorations: a case series. J Oral Implantol. 2006;32:291-9.

20. Chung KH, Chung CY, Cagna DR, Cronin RJ, Jr. Retention characteristics of attachment systems for implant overdentures. J Prosthodont. 2004;13:221-6.

21. ELsyad MA, Errabti HM, Mustafa AZ. Mandibular Denture Base Deformation with Locator and Ball Attachments of Implant-Retained Overdentures. J Prosthodont. 2016;25:656-64. 
22. Nguyen CT, Masri R, Driscoll CF, Romberg E. The effect of denture cleansing solutions on the retention of pink Locator attachments: an in vitro study. J Prosthodont. 2010;19:226-30.

23. Kleis WK, Kammerer PW, Hartmann S, Al-Nawas B, Wagner W. A comparison of three different attachment systems for mandibular two-implant overdentures: oneyear report. Clin Implant Dent Relat Res. 2010;12:209-18.

24. Jemt T, Lindquist L, Hedegard B. Changes in chewing patterns of patients with complete dentures after placement of osseointegrated implants in the mandible. J Prosthet Dent. 1985;53:578-83.

25. Jemt T, Stalblad PA. The effect of chewing movements on changing mandibular complete dentures to osseointegrated overdentures. J Prosthet Dent. 1986;55:357-61.

26. Haraldson T, Carlsson GE, Ingervall B. Functional state, bite force and postural muscle activity in patients with osseointegrated oral implant bridges. Acta Odontol Scand. 1979;37:195-206.

27. Karkazis HC. EMG activity of the masseter muscle in implant supported overdenture wearers during chewing of hard and soft food. J Oral Rehabil. 2002;29:986-91.

28. van Kampen FM, van der Bilt A, Cune MS, Bosman F. The influence of various attachment types in mandibular implant-retained overdentures on maximum bite force and EMG. J Dent Res. 2002;81:170-3.

29. Slagter AP, Bosman F, van der Glas HW, van der Bilt A. Human jaw-elevator muscle activity and food comminution in the dentate and edentulous state. Arch Oral Biol. 1993;38:195-205.

30. Diaz-Tay J, Jayasinghe N, Lucas PW, McCallum JC, Jones JT. Association between surface electromyography of human jaw-closing muscle and quantified food breakdown. Arch Oral Biol. 1991;36:893-8.

31. Schimmel M, Leemann B, Herrmann FR, Kiliaridis S, Schnider A, Muller F. Masticatory function and bite force in stroke patients. J Dent Res. 2011;90:230-4.

32. Feine JS, Maskawi K, de Grandmont P, Donohue WB, Tanguay R, Lund JP. Within-subject comparisons of implant-supported mandibular prostheses: evaluation of masticatory function. J Dent Res. 1994;73:1646-56.

33. Feine JS, Lund JP. Measuring chewing ability in randomized controlled trials with edentulous populations wearing implant prostheses. J Oral Rehabil. 2006;33:301-8.
34. Elsyad MA, Hegazy SA, Hammouda NI, Al-Tonbary GY, Habib AA. Chewing efficiency and electromyographic activity of masseter muscle with three designs of implantsupported mandibular overdentures. A cross-over study. Clin Oral Implants Res. 2014;25:742-8.

35. Schimmel M, Christou P, Herrmann F, Muller F. A twocolour chewing gum test for masticatory efficiency: development of different assessment methods. J Oral Rehabil. 2007;34:671-8.

36. van der Bilt A, van Kampen FM, Cune MS. Masticatory function with mandibular implant-supported overdentures fitted with different attachment types. Eur J Oral Sci. 2006;114:191-6.

37. van Kampen FM, van der Bilt A, Cune MS, FontijnTekamp FA, Bosman F. Masticatory function with implantsupported overdentures. J Dent Res. 2004;83:708-11.

38. Elsyad MA, Mahanna FF, Elshahat MA, Elshoukouki AH. Locators versus magnetic attachment effect on periimplant tissue health of immediate loaded two implants retaining a mandibular overdenture: a 1-year randomised trial. J Oral Rehabil. 2016;43:297-305.

39. Schincaglia GP, Rubin S, Thacker S, Dhingra A, Trombelli L, Ioannidou E. Marginal Bone Response Around Immediate- and Delayed-Loading Implants Supporting a Locator-Retained Mandibular Overdenture: A Randomized Controlled Study. Int J Oral Maxillofac Implants. 2016;31:448-58.

40. Besimo CH, Graber G, Fluhler M. Retention force changes in implant-supported titanium telescope crowns over longterm use in vitro. J Oral Rehabil. 1996;23:372-8.

41. Ohkawa S, Okane H, Nagasawa T, Tsuru H. Changes in retention of various telescope crown assemblies over longterm use. J Prosthet Dent. 1990;64:153-8.

42. Weigl P, Hahn L, Lauer HC. Advanced biomaterials used for a new telescopic retainer for removable dentures: Ceramic vs. Electroplated Gold Copings:Part I. In Vitro Tribology Effects. J Biomed Mater Res. 2000;53:320-36.

43. Fernandes CP, Glantz PO, Svensson SA, Bergmark A. A novel sensor for bite force determinations. Dental materials : official publication of the Academy of Dental Materials. 2003;19:118-26.

44. Anastassiadou V, Heath MR. The development of a simple objective test of mastication suitable for older people, using chewing gums. Gerodontology. 2001;18:79-86. 
45. Liedberg B, Owall B. Oral bolus kneading and shaping measured with chewing gum. Dysphagia. 1995;10:101-6.

46. Geertman ME, Slagter AP, van Waas MA, Kalk W. Comminution of food with mandibular implant-retained overdentures. J Dent Res. 1994;73:1858-64.

47. Weng D, Richter EJ. Maxillary removable prostheses retained by telescopic crowns on two implants or two canines. Int J Periodontics Restorative Dent. 2007;27:35-41.

48. ELsyad MA, Soliman TA, Khalifa AK. Retention and Stability of Rigid Telescopic and Milled Bar Attachments for Implant-Supported Maxillary Overdentures: An In Vitro Study. Int J Oral Maxillofac Implants. 2018;33:e127-e33.

49. Zafiropoulos GG, Hoffmann O. Five-year study of implant placement in regenerated bone and rehabilitation with telescopic crown retained dentures: a case report. J Oral Implantol. 2009;35:303-9.
50. Thiel CP, Evans DB, Burnett RR. Combination syndrome associated with a mandibular implant-supported overdenture: a clinical report. J Prosthet Dent. 1996;75:107-13.

51. Tallgren A. The continuing reduction of the residual alveolar ridges in complete denture wearers: a mixed-longitudinal study covering 25 years. J Prosthet Dent. 1972;27: 120-32.

52. ELsyad MA, Emera RM, Ibrahim AM. Effect of Labial Implant Inclination on the Retention and Stability of Different Resilient Stud Attachments for Mandibular Implant Overdentures: An In vitro Study. Int J Oral Maxillofac Implants. 2019;34:381-9.

53. Khalid T, Yunus N, Ibrahim N, Elkezza A, Masood M. Patient-reported outcome and its association with attachment type and bone volume in mandibular implant overdenture. Clin Oral Implants Res. 2017;28:535-42. 